\title{
India aims for universal health system
}

I ndia's president has declared that a universally accessible health care system is "crucial," but experts say much needs to be done before that can become a reality.

President Pranab Mukherjee said that universally accessible health care should be affordable and effective. He added that India needs a "robust health care infrastructure," "trained and motivated" health care providers, and "better access to medicines and equipment."

Mukherjee's announcement is significant, according to some Indian health leaders, health organizations and clinicians, because it strengthens a proposal contained in the National Health Policy 2015 Draft, released in Dec. 2014. That policy proposed more than doubling public spending on health care from $1.04 \%$ of gross domestic product (GDP) to $2.5 \%$ over the next five years about US $\$ 50$ billion.

In 2011, total spending on health care, both public and private, was about $4.1 \%$ of GDP; about $30 \%$ of that went to publicly funded care. As of March 2014 , only $17 \%$ of the population had health insurance.

Mukherjee agreed that the country's "public expenditure on health is meager.” Among BRIC (Brazil, Russia, India and China) nations, India's per capita government expenditure on health is US\$44; Russia spends \$809, Brazil \$474 and China \$236. "Considering that we are a sixth of humanity, a significant rise in health expenditure is urgently required to ensure universal health coverage," Mukherjee stated. India has a population of 1.25 billion.

Not surprisingly there are numerous obstacles to achieving that goal. India is a study in contrasts, said Dr. Shantanu Panja, a chief consultant at Apollo Gleneagles Hospitals in Kolkata. There are international standards of expertise and health care facilities in prominent institutes in urban areas, but a substantially

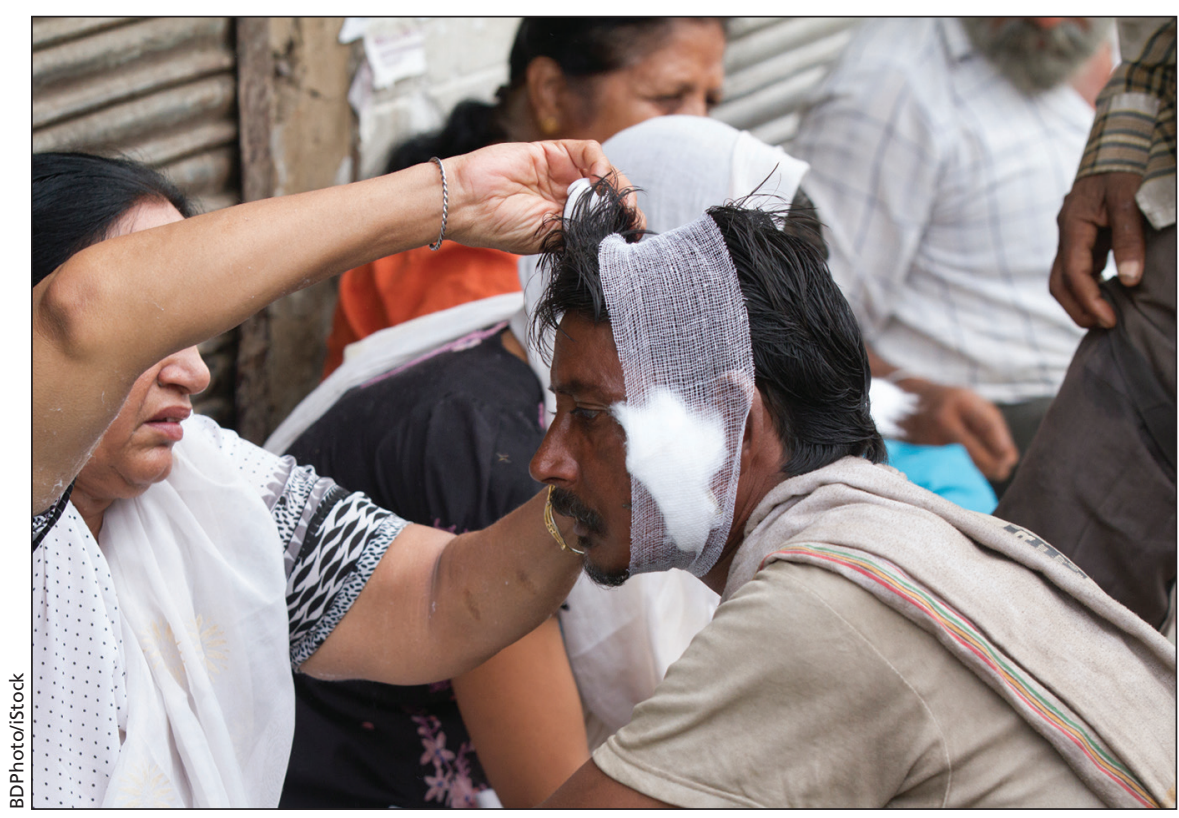

Many Indians can't afford health care. Medical volunteers through a Sikh charity set up roadside clinics in Old Delhi in 2013 to help treat the homeless.

poor health care delivery system in the remote rural areas.

Panja says emphasis should be given not only to creating new beds, but also to increasing the number of trained service providers and strengthening the infrastructure.

But efforts to beef up the health system, and increase government expenditure and health insurance coverage, are "going slow" despite several government initiatives, says Dr. Swapan Jana, a noted public health expert and secretary of the nongovernmental health think tank, the Society for Social Pharmacology.

Among BRIC nations, India has 7 hospital beds per 10000 people, compared with 23 in Brazil, 38 in China and 97 in Russia. In addition, India has 7 physicians per 10000 population, compared with 19 in Brazil, 15 in China and 43 in Russia.

Dr. Ahsan Ahmed, a consultant intensivist at the privately run Medica Institute of Critical Care in Kolkata said that only $25 \%-30 \%$ of their patients have health insurance. Many poor patients, particularly those in rural areas, opt for cheaper alternatives, such as going to an uncredentialed practitioner.

However, as Dr. Girdhar Gyani, director general of the Association of Healthcare Providers (India), in New Delhi pointed out, many Indian states are coming up with government insurance schemes for people living below the poverty level. "This needs to be improved by fixing rates of various medical procedures on a scientific basis and improving the reimbursement system from government to hospitals."

In terms of boosting the number of specialists, Gyani recommends increasing the number of postgraduate seats in medical colleges and revising the Indian Nursing Council Act, so that nurses can specialize and acquire more clinical responsibility. "We need to empower nurses so that they can share some of the work load of clinicians and also ensure career progression." - Sanjeet Bagchi, MBBS, Kolkata, India

CMAJ 2015. DOI:10.1503/cmaj.109-5084 